\title{
Traumatic Spondylolysis - A Case Report
}

\author{
Major P Chapman \\ FRCS (Ed) RAMC, Senior Specialist in Surgery \\ ${ }^{*}$ British Military Hospital, Münster BFPO 17
}

SUMMARY: The repeated minor stress of sport can produce a fatigue fracture of the neural arch. A case of unilateral spondylolysis progressing to bilateral defects and developing spondylolisthesis is described. A review of the literature is presented and the aetiology of spondylolysis is discussed.

\section{Introduction}

Spondylolysis is a bony defect in the pars interarticularis of the lumbar spine. It can be asymptomatic and so found incidently on lumbar spine radiographs, although oblique views are generally required to demonstrate the lesion clearly. The condition was first described by Robert in 1855 a year after Kilian reported four cases of spondylolisthesis'. The incidence of neural arch defect in adults is reported to be between $5.2 \%$ and $7.2 \%{ }^{2.3}$.

\section{Case Report}

A 26 year old army officer was admitted by his GP for investigation of low back pain present for three months and unresponsive to outpatient therapy. The pain was initiated by a sudden twist whilst javelin throwing. It kept him awake at night, was aggravated by bed rest and running but relieved by walking. At first he denied previous back ache but later admitted to a similar episode of pain aged fourteen years after javelin throwing.

Physical examination revealed a stiff, straight lumbar spine and reduced range of lumbar flexion. There was no neurological deficit. Radiographs of the lumbar spine demonstrated bilateral pars interarticularis defects of $\mathrm{L} 5$ with a large area of new bone formation posterior to the right pedicle (Fig 1). There was no evidence of spondylolisthesis on the lateral film.

He was treated by immobilisation in a light corset and advised to carry out sedentary work only. The symptoms settled and he was kept under review.

A radioisotope bone scan carried out nineteen months after first presentation revealed activity of the excessive callus behind the right $\mathrm{L} 5$ defect ( $\mathrm{Fig} 2$ ), and radiographs taken around the same time demonstrated a minor forward slip. There appeared to be no ossification of the pars defects.

\section{Discussion}

Various theories have been put forward to explain the bony defect. Willis considered it a congenital anomaly of ossification after failing to demonstrate the separate ossification centres postulated by Neugebauer ${ }^{2}$, whereas

\footnotetext{
* Now Registrar Department of Plastic Surgery,

Addenbrookes Hospital, Cambridge, CB2 $2 Q Q$
}

Batts argued that if the lesion were congenital then its incidence in foetal spines would correlate with that in adults, but after radiological examination of 200 foetal spines he concluded that spondylolysis was an acquired defect ${ }^{4}$. Rowe and Roche were unable to produce pars separation in foetal spines by manipulation and felt they

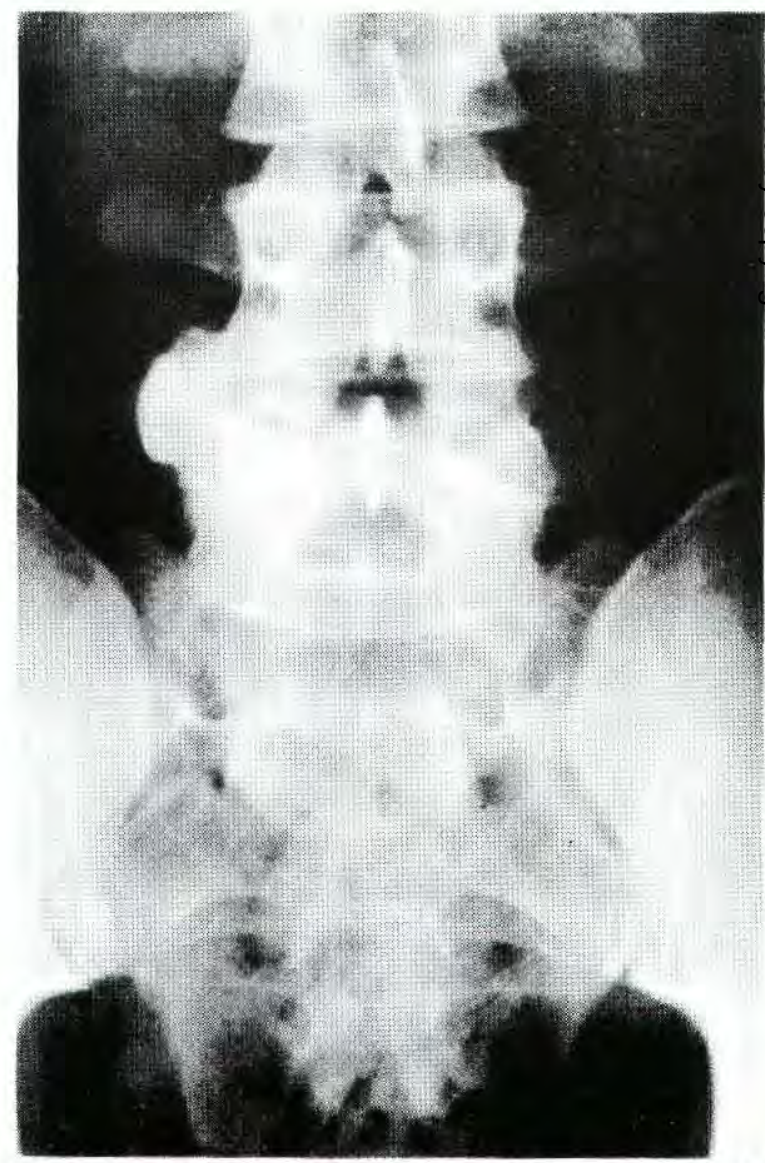

Fig 1. Lumbar spine radiograph taken a few days prior to hospital admission showing excess mature bone formation around the fifth lumbar vertebra. 


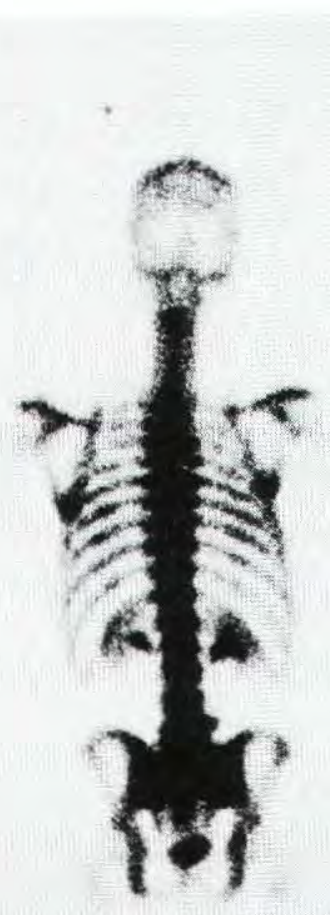

Fig 2. Bone scan with $428 \mathrm{MBq} 99 \mathrm{~m}$ Tc-DPD, viewed from behind, showing increased uptake of isotope from the fifth lumbar vertebra on the right side.

could rule out birth trauma as a causative factor ${ }^{5}$. In a study of Eskimo skeletons the progressive and higher than normal incidence of defects suggested as a cause the repeated trauma and posture of traditional Eskimo life $^{6}$. Consanguinity studies showed a high incidence of asymptomatic spondylolysis in the near relatives of patients presenting with spondylolisthesis supporting the theory of a hereditary basis for the lesion ${ }^{7}$. A review of eighteen preserved museum skeletons with spondylolysis demonstrated that in sixteen the cleft was located between the downward projection of the inferior articular surface of the vertebra above and the upward projecting superior articular facet of the vertebra below, implying that a mechanical pincer effect might be responsible ${ }^{\varsigma}$. More recently spondylolysis has been produced mechanically in isolated cadaveric lumbar vertebra ${ }^{9}$ and in a mathematical model, relatively little force was required to shear the pars interarticularis in a lumbar spine flexed under load ${ }^{10}$. A study carried out in Japan revealed spondylolysis in $27 \%$ of athletes who admitted to either acute trauma or repeated stress of the spine ${ }^{11.12}$.

Although in this case there is a history of recent trauma the maturity of the new bone formation posterior to the defect could indicate non-union of a stress fracture. Acute fracture would be expected to produce callus at the defect rather than posteriorly.

It is postulated that repeated athletic stress caused a fracture of the right pars interarticularis originally. This fracture failed to unite and the resultant instability caused a reactive, excessive bone reaction around a stressed facet joint. Continued chronic trauma to an already weakened neural arch caused fracture of the left pars around the time of first hospital admission allowing spondylolisthesis to develop subsequently.

Acknowledgements
I wish to thank Col D G Stock FRCS L/RAMC whi़्षे initially suggested that this paper be prepared and Lt Co $\frac{\rho}{\mathbb{Q}}$ R J M MacDonald FRCS(ED) RAMC for valuable criticism and permission to report on his patient. D Med Kramps of the Westfälische Wilhelms-Univerität Münster very kindly provided the radio isotope scan.

\section{REFERENCES}

1. Sullivan C R and Bickeli. W H. The problem of traumatic spondylolysis. Am J Surg 1960; 100: 698- 708.

2. WILLIS T A. The separate neural arch. J Bone Joint Surg $1931 ; 13: 709-721$.

3. Moreton R D. Spondylolysis. J A M A 1966; 195: 159162.

4. Batrs M. The etiology of spondylolisthesis. J Bone Joint Surg 1939; XXI: 879-884.

5. Rowe G G and Roche M B. The etiology of separate neural arch. J Bone Joint Surg 1951; 35-A: 102-110.

6. StEWART T D. The age incidence of neural-arch defects in Alaskan Natives, considered from the standpoint of etiology. J Bone Joint Surg 1953; 35-A: 937-950.

7. WILTSE L L. Etiology of spondylolisthesis. Clin Orthop 1957; 10: 48-59.

8. NATHAN H. Spondylolysis - its anatomy and mechansim of development. J Bone Joint Surg 1959; 41-A: 303-317.

9. Cyron B M, Hutton W C and Troup J D G. Spondylolytic fractures. J Bone Joint Surg 1976; 58-B: 462-466.

10. Hutton W C, Stott J R R and Cyron B M. Is spondylolysis a fatigue fracture? Spine 1977; 2: 202-209.

11. ICHIKAWA N, et al. An aetiological study on spondylolysis from a biomechanical aspect. Br J Sports Med 1982; 16: 135-141.

12. Murray R O and Colwill M R. Stress fractures of the pars interarticularis. Proc R Soc Med 1968; 61: 555-557. 